\title{
Evoked potentials and contingent negative variation during treatment of multiple sclerosis with spinal cord stimulation
}

\author{
E M S E DGW ICK, L S ILLIS, R C TALLIS, \\ A R D THOR N T O N, P A B R HAM, E EL-NEGAMY, \\ T B D OCHERTY, J S SOAR, S C SPENCER, \\ A ND F M T A YLOR
}

From the Wessex Neurological Centre, Southampton General Hospital, and the Institute of Sound and Vibration Research, University of Southampton, Southampton, and the Royal Army Medical College, Millbank, London

SUMMARY Cervical somatosensory evoked potentials, brainstem evoked potentials, visual evoked potentials, and the cerebral contingent negative variation were recorded in patients with definite multiple sclerosis before, during, and after spinal cord stimulation. Improvements were seen in the cervical somatosensory and brainstem evoked potentials but neither the visual evoked potential nor the contingent negative variation changed in association with spinal cord stimulation. The results indicate that spinal cord stimulation acts at spinal and brainstem levels and that the clinical improvements seen in patients are caused by an action at these levels rather than by any cerebral arousal or motivational effect. The evoked potentials were not useful in predicting which patients were likely to respond to stimulation.

Epidural spinal cord stimulation (SCS) has been used for some years in the management of multiple sclerosis (Cook and Weinstein, 1973; Illis et al., 1976). Illis et al. (1980) have published the early results of a trial of SCS in 19 patients with multiple sclerosis and showed a reduction of neurological deficit which was due to modification of central nervous system function and not to natural fluctuations in the disease, to a placebo effect, to increased motivation, or to training. Neurophysiological investigations were carried out on many of the patients in the trial and a preliminary report of some of the findings has been given (Sedgwick et al., 1978; Abraham et al., 1978).

Cervical somatosensory evoked potentials (CSEP), brainstem auditory evoked potentials (BAEP), visual evoked potentials (VEP), and the contingent negative variation (CNV) were recorded in patients with definite multiple sclerosis before, during, and after treatment by SCS. It was proposed that, if SCS worked by modifying central nervous system function, changes would be ob-

Address for reprint requests: Dr E M Sedgwick, Wessex Neurological Centre, Southampton General Hospital, Southampton SO9 4XY.

Accepted 1 June 1979 served in the evoked potentials which would give some indication of the site and mode of action of SCS. The short latency components of evoked potentials are relatively insensitive to psychological influence (Shagrass, 1977). Any substantial changes in these early components would not, therefore, be attributed to psychological effects such as the placebo phenomenon. The CNV, however, is a slow event-related cortical potential which is classically susceptible to modification by psychological factors. It was, therefore, considered to be particularly suitable to investigate the possibility that the improvement in symptoms of multiple sclerosis after SCS was at least partly attributable to a placebo effect.

There have been no previous studies of the CSEP, BAEP, VEP, or CNV during SCS, but Larson et al. (1974) and Blair et al. (1975) report changes in the late components of the cortical somatosensory evoked potential in patients undergoing SCS for pain. Blair et al. (1975) showed a reduction of amplitude of late components (more than $200 \mathrm{~ms}$ ) but the short latency responses were unchanged by SCS. These studies were done on patients with pain and normal nervous systems 
whereas the present paper concerns multiple sclerosis patients with damaged nervous systems and abnormal evoked potentials.

\section{Subjects and methods}

The patients studied were subjects for a trial of spinal cord stimulation in multiple sclerosis. All had definite multiple sclerosis according to Schumacher's criteria and in addition had abnormal evoked responses. All had been in a clinically stable state for at least six months before the trial, and only one had a clinical relapse during the period covered by this study. The clinical details of the subjects are included in the preceding paper (Illis et al., 1979).

CERVICAL SOMATOSENSORY EVOKED POTENTIALS

The method of recording the CSEP has been reported in full (El-Negamy and Sedgwick, 1978). Briefly, recordings were taken from electrodes on the skin at the seventh cervical vertebra and a cranial reference electrode at Fz (10-20 System). The right median nerve at the wrist was stimulated at three times sensory threshold twice per second. The signals were amplified $(8 \mathrm{~Hz}-10 \mathrm{kHz})$ and analysed by averaging 256-300 epochs with a PDP-12 computer.

Eight patients were studied before and during SCS but the spinal cord stimulator was switched off during the recording. The initial recording was carried out at 3-18 days before spinal cord stimulation and again after 4-22 days of stimulation.

\section{AUDITORY BRAINSTEM EVOKED POTENTIALS}

The method of recording auditory brainstem potentials (BAEP) has been described in detail by Thornton (1975a). Briefly, recordings were taken from left and right sides of the head on 10 patients before and during SCS (Fz-ground, left and right mastoid/vertex signal pairs). Four patients were tested on more than one occasion, giving a total of 30 sets of results. Click stimuli, presented via screened TDH-49 earphones at a rate of 10 per second, were used and 2000 presentations were taken to obtain each averaged response. On each occasion, and for each condition, at least three repeat response recordings were made. The data were averaged using a $30 \mathrm{~ms}$ window and a recording bandwidth of $100 \mathrm{~Hz}$ to $3 \mathrm{kHz}$ with a PDP-12 computer. The amplitudes and latencies of the various BAEP components were measured. With monaural stimulation, if a component, say $\mathrm{N} 3$, is delayed then the succeeding components (N4 and N5) are also delayed. Thus, the latency value of $\mathrm{N} 5$ may be used to indicate any delay in response latency for components $\mathrm{N} 1$ to N5. The nomenclature here is that proposed by Sohmer and Feinmesser (1967).

\section{VISUAL EVOKED POTENTIALS}

Silver-silver chloride disc electrodes were attached to cleaned skin at positions $0_{1}, 0_{2}$, and $\mathrm{Fz}(10-20$ System) and their resistance checked to be less than $2 \mathrm{k}$ ohms. Recordings were made between $0_{1}-\mathrm{Fz}$ and $0_{2}-\mathrm{Fz}$. Amplification was by a Van Gogh EP8 portable EEG machine with a time constant of $0.3 \mathrm{~s}$ and $\mathrm{HF}$ cut-off at $75 \mathrm{~Hz}(3 \mathrm{~dB})$. In early studies a Devices "Neurolog" averager was used giving 256 points for an averaging window of $250 \mathrm{~ms}$. Later a Datalab DL4000 averager was used giving 1000 points in $250 \mathrm{~ms}$. Thirty-two, 64 , or 128 sweeps were averaged and then photographed from an oscilloscope or plotted on an X-Y plotter. During recording the EEG machine was run to check for muscle and other artefacts.

Stimulation of one eye at a time was by a Digitimer pattern reversal stimulator which has a $150 \mathrm{~mm}$ square screen placed to subtend an angle of $17^{\circ}$ at the subject (screen to subject distance $=500 \mathrm{~mm}$ ). Each check subtended an angle of $51.5^{\prime}$ at the eye. The luminance of the checks was 2.8 to 88 lux for the black and white squares respectively.

The subject sat, with one eye covered, and fixated a pin head in the centre of the checkerboard screen. His eye fixation was monitored during the run by the recordist. Any runs with excessive artefact on the EEG or showing poor eye fixation were repeated. After time and amplitude calibration pulses had been recorded the traces were analysed by eye. The latency and amplitude figures from $0_{1}$ and $0_{2}$ electrodes were averaged to give a mean latency and amplitude from each eye.

CONTINGENT NEGATIVE VARIATION

Full details of the method used in the first series experiments have been published by Abraham et al. (1979). Briefly, recording was from a $\mathrm{Cz}$ scalp electrode to paired ear lobes, with eye movement compensation as described by McCallum and Walter (1968), using an amplifier with a $10 \mathrm{~s}$ time constant and a $70 \mathrm{~Hz}$ frequency cut-off. A simple CNV paradigm consisting of a distinct warning click through earphones followed one second later by a train of light flashes (16/s) from a stroboscope $250 \mathrm{~mm}$ in front of the subject was employed. Subjects were instructed to terminate the flashes as quickly as possible by pressing a button. The intertrial interval varied irregularly between 5 and 15 seconds. Contingent negative variations were recorded, with and without distracting stimuli, 
before implantation of the spinal cord electrodes and again after several days of SCS. On the second visit recordings were again made with and without distraction, with the spinal cord stimulator switched on and off in each condition. Additionally, the stimulator was itself used to provide the "warning" and "imperative" stimuli, replacing in turn the click and train of light flashes, and brief bursts of mechanical stimulation of the skin were similarly employed in place of these two stimuli in an otherwise identical CNV paradigm.

In a subsequent series of experiments, in which seven subjects, including three from the earlier series, participated, the effect of motivation was studied systematically. In this series the subjects' eyes were open and fixated during the CNV trials which were presented in blocks of 10 separated by short rest periods. Before implantation, 20 trials, in which the subject was encouraged to respond to the imperative stimulus as quickly as possible, were followed by another 20 in which this encouragement was omitted, and then another 20 in which it was renewed. After implantation and several days of SCS the sequence of 20 motivated and 20 unmotivated trials alternated for a total of 120 trials. In addition, after every alternate block of 10 trials the stimulator was switched on or off. Artefact-free trials in each of the resulting four conditions were averaged separately off-line with a PDP 12 computer (eight trials from each block of 10).

\section{Results}

CERVICAL SOMATOSENSORY EVOKED POTENTIALS A normal cervical somatosensory potential after median nerve stimulation is shown in fig 1 with the different components N9, N11, N13, N14, and N20 identified. Figure 2 shows traces from three patients with multiple sclerosis who had SCS. The upper trace of each pair shows the potential recorded during the week before stimulation began, while the lower trace was recorded after four to nine days of continuous stimulation. An improvement towards a normal CSEP is apparent.

Figure 3 shows the change in amplitude of the different components of the CSEP in the eight patients studied before and after stimulation. The second recording was done after 4-11 days of stimulation. Particular importance is attached to the N9 potential which was normal in all cases and did not change significantly. N9 is generated by the afferent volley as it traverses the brachial plexus (Jones, 1977). One can, therefore, be cer-

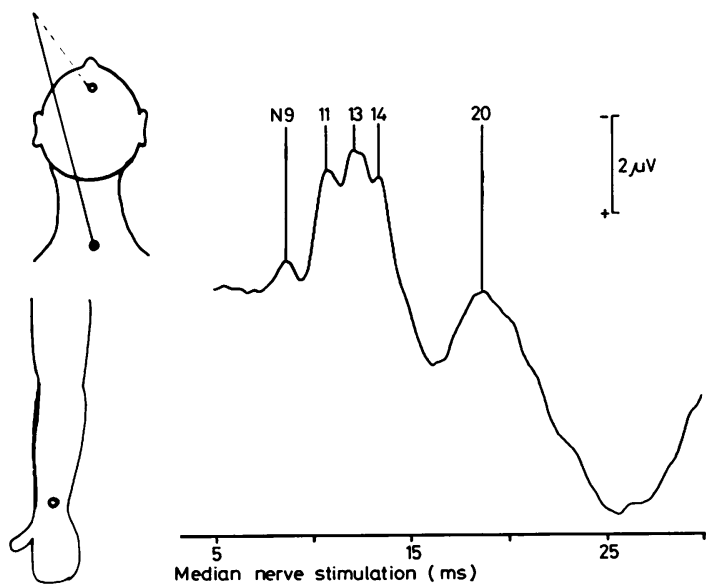

Fig 1 Normal CSEP recorded from electrodes on the seventh cervical vertebra and $F z$. The median nerve at the wrist was stimulated. The components N9, N11, $N 13, N 14$, and $N 20$ of the CSEP are labelled.

tain that an afferent volley of standard size reached the cervical cord on each occasion.

All eight patients had absent or low amplitude CSEPs but the N11 potential recovered during SCS in seven of these patients, the N13 in five, and the N14 in four. The recovery in amplitude was to the low normal range. The earliest recorded improvement of potentials was after four days of SCS.

The question arose whether these changes in the CSEP occur normally or perhaps in association with hospitalisation rather than with SCS. Repeated observations on three of the eight patients show that the abnormal CSEP was prone to small variations but the change with SCS was marked and the potential returned to its former state after SCS. The results from one patient are illustrated in fig 4 which shows improved responses during SCS except during a clinical relapse when the patient's neurological condition and the CSEP deteriorated. She improved clinically afterwards as did the CSEP. Again the N9 component remained normal throughout.

In three additional patients who had absent potentials during the four to seven days before SCS, recordings were made daily. After one or two days of SCS the CSEP had appeared and in one case was of normal amplitude. Subsequently the potentials declined slightly but then remained stable for the remainder of the study period which was up to 25 days.

AUDITORY BRAINSTEM EVOKED POTENTIALS

Similar results were obtained with the BAEP. 


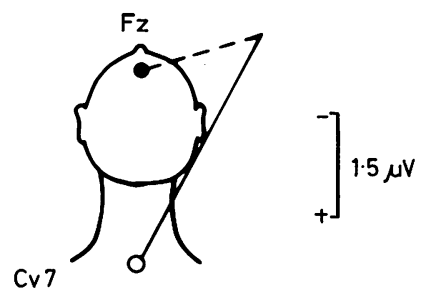

A

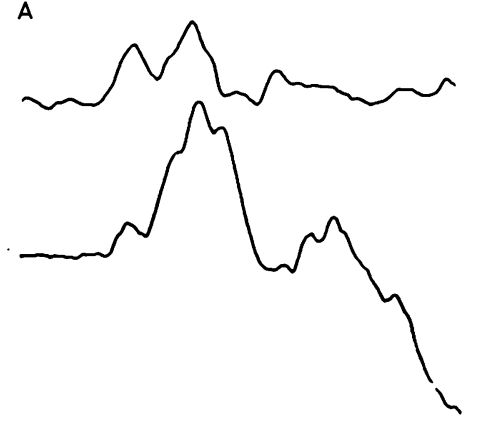

B
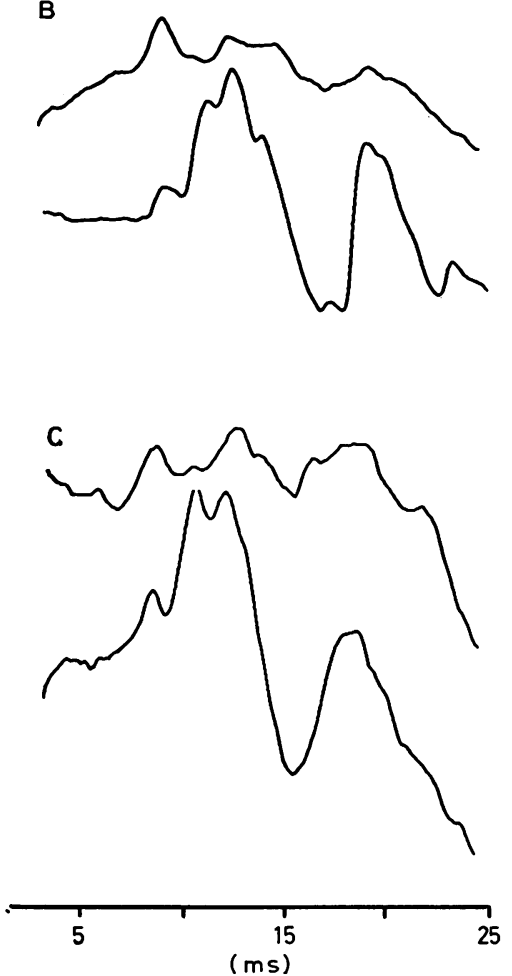

Fig 2 Cervical somatosensory evoked potentials of three patients $(A, B$, and $C)$ with multiple sclerosis are shown. The upper trace of each pair was recorded before SCS and the lower trace after at least four days of SCS. Note the normal N9 component in each case.
Changes in both amplitude and latencies of responses were found but the most consistent change with multiple sclerosis was the latency of the components. All patients had normal audiograms and a normal cochlear nerve response. This indicated that there was no peripheral disorder and an adequate neural input to the auditory brainstem. Figure 5 shows the set of the five main BAEP components recorded from a patient before and after SCS. There were, as is generally found in these cases, variable changes in response amplitude. However, a decrease in the latency of N5 with SCS was noted.

Data were obtained from left and right sides of the heads of 10 patients. Some were tested more than once before and during temporary and permanent SCS, giving a total of 30 results. These gave 11 which showed a statistically significant improvement with SCS; 15 showed a nonsignificant improvement, and four showed a nonsignificant worsening. In one patient, who went through two periods of relapse, the latencies of the BAEP reflected these worsenings and improvements. For each test condition, three repeat measurements were taken. This enabled the consistent events in each waveform to be identified and the mean of the three values was taken to give the latency measure. If the latency after SCS had decreased by more than two standard deviations from the value before SCS, the change was considered significant. The standard deviation values of the latencies were those obtained from normal subjects (Thornton, 1975b).

Restriction of the analysis to the results obtained from the first time that a patient was implanted gave 20 results (left and right sides from 10 patients) which are summarised in table 1 . Depending upon their hearing level, each patient was stimulated at either $80 \mathrm{~dB}$ or $70 \mathrm{~dB}$ SL. The results were analysed, as described above, and showed significant improvements after SCS. Here, for reasons of consistency and compatibility with the other evoked potential data, the results shown in table 1 have been standardised to $80 \mathrm{~dB}$ SL so that the mean latency values before and after SCS could be presented simply. For the $70 \mathrm{~dB}$ SL records, the latency value was expressed as a deviation from the normal mean value in terms of a multiple of normal subject standard deviations. This was taken as an equivalent deviation at $80 \mathrm{~dB}$ SL and, from a knowledge of the normal mean value and standard deviation at $80 \mathrm{~dB}$ SL, a latency value, normalised to $80 \mathrm{~dB}$ SL, could be calculated. The statistical significance of the results has not been altered by this transformation 


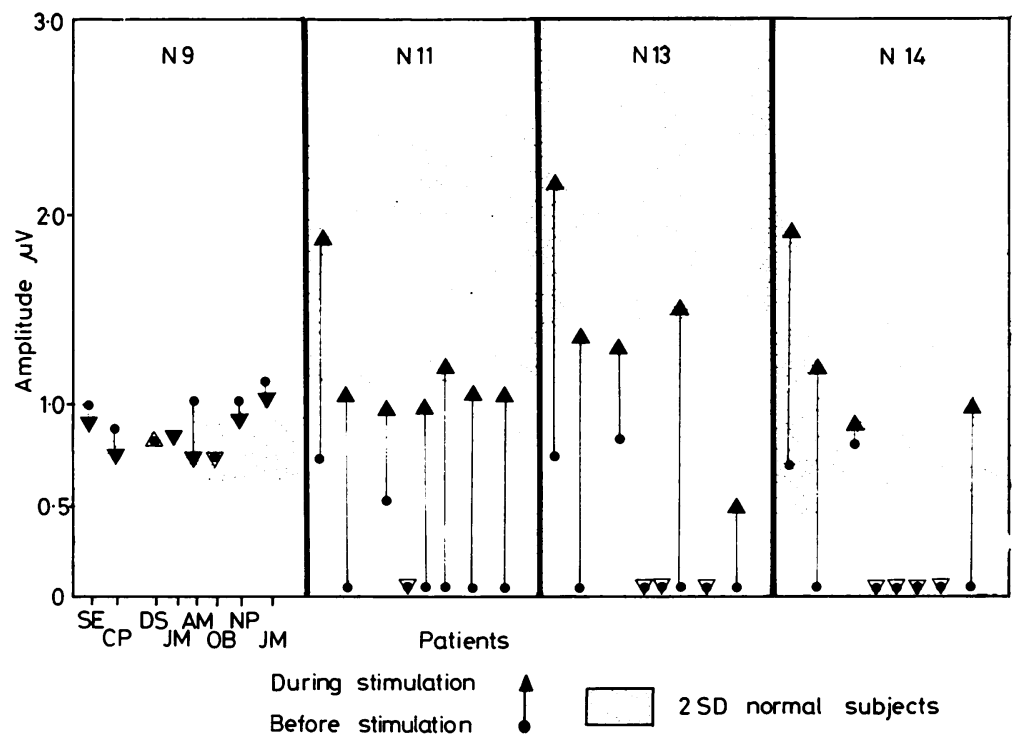

Fig 3 Amplitudes of the components of the cervical somatosensory evoked potentials are plotted before $(\bullet)$ and after (A) spinal cord stimulation in eight patients. The shaded areas represent two standard deviations of normal. The patients are identified by initial at the base of the N9 column.

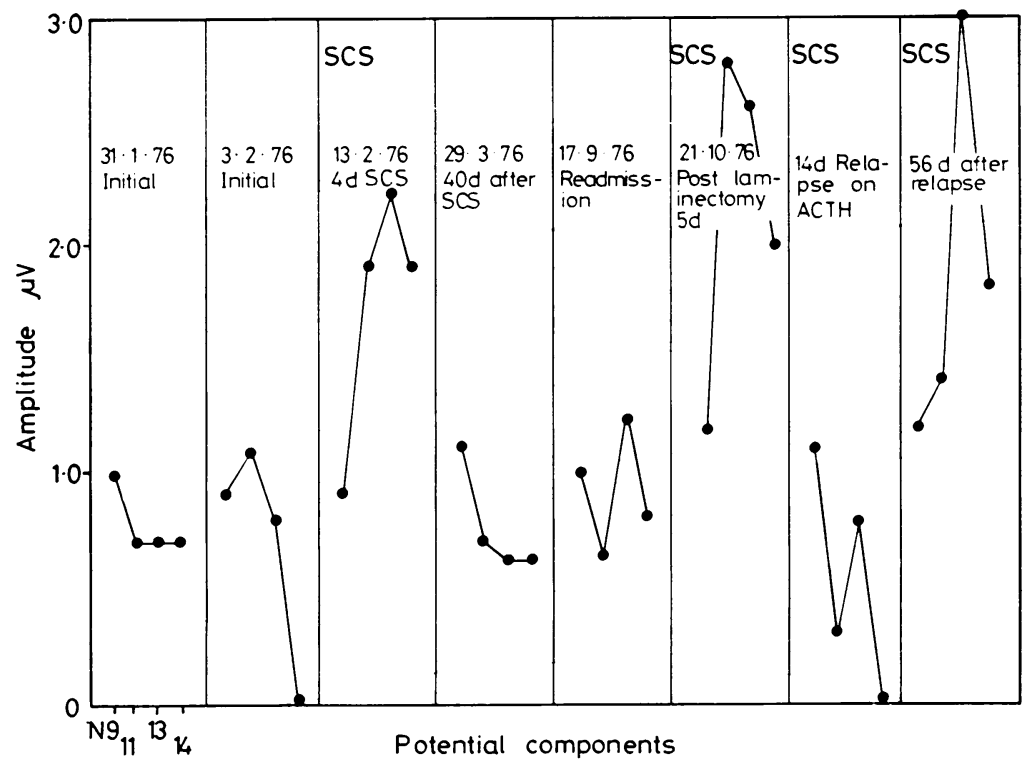

Fig 4 Amplitudes of the different CSEP components are plotted for one patient who was studied on eight occasions. The components are identified at the base of the first column. Columns headed SCS indicate that the spinal cord was being stimulated at that time. Note the normal $N 9$ on each occasion, the increase in amplitude recorded during SCS and the reduction during $a$ relapse of inultiple sclerosis which was followed by recovery. The laminectomy for permanent implantation of the SCS electrodes was at $T 2$ and 3 vertebrae.

which was used only to permit comparisons between the different evoked potential measures. The variance of the latency values after SCS is significantly smaller than that found before SCS. Thus, a Wilcoxon matched-pairs signed-ranks test was used to examine the difference in the mean latency values. The single-tailed test showed that the mean latency after SCS was smaller, that is nearer to normal values, than that obtained before SCS, at the $p=0.005$ level of significance. Thus, a highly significant reduction in response latency was found after SCS.

The repeat measurements taken in each test session showed no significant differences, and no differences in the BAEP were found with the stimulator on or after it had been switched off for short periods of about 10 to 20 minutes. Significant changes were found only after several days had elapsed after the removal of the original temporary implants given to some of the patients. As would 


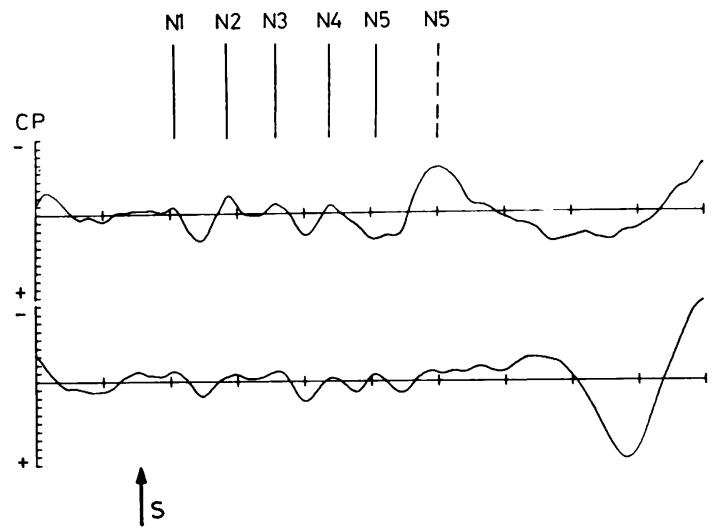

Fig 5 Brainstem evoked potentials recorded from one subject with multiple sclerosis before SCS (above) and after a few days of SCS (below). The components of the BAEP are labelled. Note the decrease in latency of N5 after a period of SCS. Click stimuli were given at the arrow. Each division on the ordinate $=50 \mathrm{nV}$ and one division on the abscissa $=1.5 \mathrm{~ms}$.

Table 1 Auditory brainstem evoked potentials: summary of the 20 results obtained from 10 patients before and after SCS

\begin{tabular}{|c|c|c|c|c|}
\hline & \multicolumn{4}{|c|}{ N5 Latency values* } \\
\hline & $\begin{array}{l}\text { Before } \\
\mathrm{ms}\end{array}$ & $\begin{array}{l}\text { After } \\
m s\end{array}$ & Test & Significance \\
\hline Mean & 7.88 & 7.52 & WMPSR $†$ & $\begin{array}{l}t=14.5 \\
\mathrm{p}<0.005\end{array}$ \\
\hline SD & 0.54 & 0.34 & - & - \\
\hline VAR. & 0.29 & 0.12 & $\mathbf{F}$ & $\begin{array}{l}F=2.43 \\
p<0.05\end{array}$ \\
\hline
\end{tabular}

*Standardised to a stimulation level of $80 \mathrm{~dB}$ SL.

†Wilcoxon matched-pairs signed-ranks test.

be expected in testing a group of patients with different degrees of severity of the pathology being investigated, the variance of the results, both before and after SCS, was significantly greater than that found in normal subjects.

In addition, in those patients who were tested before and after SCS on several occasions, the intra-subject variance before SCS was significantly greater than the variance after SCS. These findings are in agreement with those of Robinson and Rudge (1978) who reported that the BAEP waveform may be less stable in multiple sclerosis than in normal subjects.

\section{VISUAL EVOKED POTENTIALS}

Visual evoked potentials were recorded in all patients considered for spinal cord stimulation and all in this study had a prolonged $\mathrm{P} \overline{100}$ latency. Repeated studies were done on 11 patients before and during stimulation. Four patients were studied twice as they had periods of SCS separated by three to six months-there were, therefore, 15 sets of results for analysis. The interval between the two recordings was $4-44$ days (mean $=18.7 \pm$ 11.0) and at the second recording the patients had received at least four days of SCS and usually 10-14 days. Spinal cord stimulation was continued up to the time of recording but switched off during recording to avoid artefact contamination of the record. There were no identifiable potentials from one eye and the amplitudes were not determined for one subject.

In this laboratory, the $\overline{\mathbf{P} 100}$ latency from 43 normal subjects was $99.6 \pm 6.99 \mathrm{~ms}$ and the upper limit of normal is taken as $118 \mathrm{~ms}$. The normal amplitude was $10.78 \pm 5.80 \mu \mathrm{V}$. All subjects with multiple sclerosis in this study had abnormally delayed potentials which were usually of low amplitude. Table 2 shows the amplitude and latency of the $\mathrm{P} \overline{\mathbf{1 0 0}}$ evoked from the eyes of the subjects before and during SCS. There was no statistically significant change associated with SCS.

Table 2 Amplitude and latency of the $P \overline{100}$ of the visual evoked potential recorded before and after SCS in 11 subjects. The significance, $p$, was determined by the paired $t$ test and was $>0.1$ in all cases. One subject had no detectable response from one eye and amplitudes were not determined from one other subject

\begin{tabular}{|c|c|c|c|c|c|c|}
\hline \multirow[t]{2}{*}{$P \overline{I 00}$} & \multicolumn{3}{|c|}{ Right eye } & \multicolumn{3}{|c|}{ Left eye } \\
\hline & Before & After & $p$ & Before & After & $p$ \\
\hline \multicolumn{7}{|c|}{ Amplitude $(\mu \mathrm{V})$} \\
\hline $\begin{array}{l}\text { Mean } \\
\text { SD } \\
\mathbf{N}\end{array}$ & $\begin{array}{l}5.41 \\
2.67 \\
9.0\end{array}$ & $\begin{array}{l}6.64 \\
2.75 \\
9.0\end{array}$ & NS & $\begin{array}{c}5.73 \\
2.50 \\
10.0\end{array}$ & $\begin{array}{c}6.45 \\
3.57 \\
10.0\end{array}$ & NS \\
\hline \multicolumn{7}{|c|}{ Latency (ms) } \\
\hline $\begin{array}{l}\text { Mean } \\
\text { SD } \\
\mathbf{N}\end{array}$ & $\begin{array}{c}144.7 \\
22.25 \\
10.0\end{array}$ & $\begin{array}{c}143.3 \\
22.77 \\
10.0\end{array}$ & NS & $\begin{array}{c}145.6 \\
19.88 \\
11.0\end{array}$ & $\begin{array}{c}146.8 \\
15.64 \\
11.0\end{array}$ & NS \\
\hline
\end{tabular}

\section{CONTINGENT NEGATIVE VARIATION}

The CNVs of the multiple sclerosis patients were of normal form and amplitude as expected in patients without clinical hemisphere lesions.

The CNVs obtained when the stimulator was used to provide the "warning" and "imperative" stimuli were of similar form and amplitude to those obtained by cutaneous stimulation, indicating that there was an adequate neural input to the cortex and that the subjects were consciously aware of that input.

The CNVs were decreased by distracting stimuli by a mean of $6 \mu \mathrm{V}$ and increased by encourage- 
ment by a mean of $4 \mu \mathrm{V}$, showing that the CNV could be varied by psychological factors in these subjects, as is usually the case.

Table 3 shows the CNV amplitudes of seven patients before and after SCS, with and without motivation, with the stimulator switched on and off. The combined averages of the seven subjects are shown in fig 6 .

In table 4 a statistical analysis of the results is summarised and shows a clear difference between the motivated and unmotivated states. There was no difference, however, in the CNV before and after implantation of electrodes and SCS, whether or not the spinal cord stimulator was switched on or off during the later recording session.

\section{Discussion}

EVOKED POTENTIAL CHANGES IN MULTIPLE SCLEROSIS The question arises whether the changes in CSEP and BAEP seen in association with SCS are fortuitous or directly related to the stimulation. The CSEP in normal subjects is very stable from day to day and year to year (El-Negamy, 1978). All our patients had abnormal evoked potentials but their disease was clinically inactive throughout the time of this study and for the preceding six months. One patient, shown in fig 4, eventually had a relapse and showed a deteriorated CSEP at that time. Matthews and Small (1979) and Robinson and Rudge (1978) studied the evoked potentials of multiple sclerosis patients over periods of up to 42 months. Their findings were that the evoked potentials of clinically "stable" patients did not change unless a relapse occurred. Our own experience has been that, in the absence of a relapse, only minor changes in CSEP amplitude occur in the absence of SCS. If these changes were random and unrelated to SCS one would expect to see increased and decreased CSEPs from time to time unrelated to SCS but no such changes have been observed. Present evidence, therefore, suggests that any change in our patients' evoked potentials would be unlikely unless related to SCS.

CERVICAL SOMATOSENSORY EVOKED POTENTIALS

Abnormal CSEPs have been reported in a high proportion of patients with definite multiple sclerosis (Small et al., 1978). The usual finding was a reduction in amplitude or even absence of a response. Prolonged latency was a less common finding and we have not observed it in this series.

If one can accept that the increased amplitudes are related causally to SCS then whatever systems generate the CSEPs must have been facilitated or enhanced by it. The N9 component is generated in the medial cord of the brachial plexus (Jones, 1977; El-Negamy, 1978). This potential was constant throughout the study indicating an equal afferent volley on each occasion. The N11 component probably originates in the dorsal horn of the spinal cord and is considered to be equivalent to the N1 cord dorsum potential seen in animals (El-Negamy and Sedgwick, 1978; Sedgwick and Soar, 1979) which is generated by synaptic mechanisms in the dorsal horn. It therefore follows that the afferent volley becomes more effective in engaging the dorsal horn synaptic mechanisms after a period of SCS. By the same argument, the generators of N13 and N14 are also facilitated by SCS but the location of these generators is less certain. They are thought to be the nucleus cuneatus for N13 and the thalamus for N14.

\section{AUDITORY BRAINSTEM EVOKED POTENTIALS}

The conclusions from these data are similar to those discussed above for the cervical somatosensory responses. In some of the patients, statistically significant improvements, of magnitudes much greater than normal response variability, have been associated with SCS. Similarly the problems remain concerning the mechanisms involved in

Table 3 Mean CNV amplitude in microvolts during $200 \mathrm{~ms}$ before $S 2$

\begin{tabular}{|c|c|c|c|c|c|c|}
\hline \multirow[t]{3}{*}{ Subjects } & \multicolumn{2}{|c|}{ Before electrode implantation } & \multicolumn{4}{|c|}{ After electrode implantation and stimulation } \\
\hline & \multirow[t]{2}{*}{ Motivated } & \multirow[t]{2}{*}{ Unmotivated } & \multicolumn{2}{|c|}{ During stimulation } & \multicolumn{2}{|c|}{ Without stimulation } \\
\hline & & & Motivated & Unmotivated & Motivated & Unmotivated \\
\hline $\begin{array}{l}1 \\
2 \\
3 \\
4 \\
5 \\
6 \\
7\end{array}$ & $\begin{array}{l}15 \\
17 \\
10 \\
17 \\
18 \\
16.5 \\
14.5\end{array}$ & $\begin{array}{r}12 \\
9 \\
9 \\
10 \\
13 \\
10 \\
15\end{array}$ & $\begin{array}{r}13 \\
16 \\
6 \\
26 \\
14 \\
14 \\
14\end{array}$ & $\begin{array}{r}11 \\
11 \\
10 \\
14 \\
10 \\
12 \\
9\end{array}$ & $\begin{array}{r}10 \\
19 \\
8 \\
24 \\
16 \\
16 \\
13\end{array}$ & $\begin{array}{r}10 \\
13 \\
8 \\
19 \\
10 \\
9 \\
11\end{array}$ \\
\hline Mean & 15.4 & 11.1 & 14.7 & 11.0 & 15.1 & 11.4 \\
\hline $\mathbf{S D} \pm$ & 2.7 & 2.3 & 5.9 & 1.6 & 5.4 & 3.7 \\
\hline
\end{tabular}



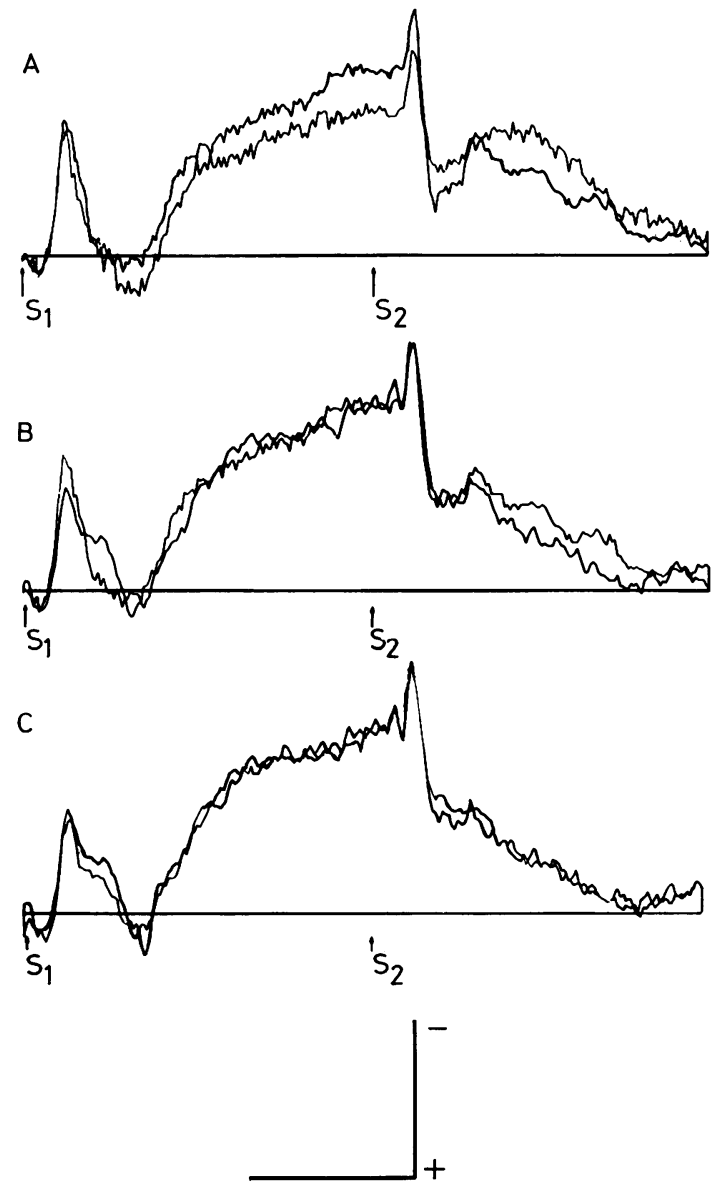

Fig 6 Combined averages of CNVs of seven subjects are shown. In $A$ both traces were obtained after SCS with motivation (upper trace) and unmotivated (lower trace). In $B$ the traces represent the combined average before SCS and after a period of SCS. There is no difference. The CNVs obtained with the stimulator switched on or off are shown in C. Again there is no difference. In $A$ and $C$ each trace was derived from 336 responses, in $B$ both traces were derived from 672 responses. Calibration $500 \mathrm{~ms}$ and $10 \mu \mathrm{V}$.

changes in responses from the midbrain level. There appears to be a causal link between SCS and the improvements found both in the clinical state and in the BAEP of some of the patients undergoing SCS. Further studies on larger numbers of patients will help to elucidate whether such changes are related directly to the stimulation procedure.

VISUAL EVOKED POTENTIALS

The $\mathrm{P} \overline{100}$ of the pattern reversal visual evoked potential did not change in amplitude or latency in association with SCS. The other components of the VEP were not analysed systematically as they could not be identified reliably in these recordings which were of low amplitude and distorted by multiple sclerosis. Some patients reported improved vision as a result of SCS but this may be part of their increased sense of well-being or increased endurance, or perhaps by some improvement in eye movement control. It was not accompanied by any change in visual acuity or in the VEP.

CONTINGENT NEGATIVE VARIATION

Contingent negative variations in our patients were normal. Spinal cord stimulation reached the cortex and consciousness but, contrary to our expectations, did not change the CNVs. The clinical results of SCS were unlikely, therefore, to have been mediated via cortical excitement as measured by CNV.

The CNVs in our patients were subject to the classical changes produced by distraction and fluctuations in motivation. And yet the implantation procedure and a period of SCS sufficient to initiate clinical improvement was not followed by any change in $\mathrm{CNV}$, nor was SCS accompanied by any change in CNV during stimulation. It seemed unlikely, therefore, that the clinical results of SCS were caused by increased motivation as was suggested by Hawkes et al. (1978).

SITE OF ACTION OF SPINAL CORD STIMULATION

These physiological studies were objective measures of central nervous system function at four different levels: the spinal cord (CSEP), the brainstem (BAEP), the primary and secondary visual cortex (VEP), and higher cortical mechanisms (CNV). The observation of changes in potentials towards normal only in the spinal cord and brainstem suggests that SCS has an action at these levels and does not produce its effects by less specific arousal or other mechanisms. Further, ElNegamy and Sedgwick (1978) gave evidence that the Ni1 CSEP was generated by the dorsal horn synapses. The N $\overline{13}$ also improves and it has been suggested that this arises from the nucleus cuneatus. Both these sites are locations of the first synapses in the afferent pathway. The N5 of the BAEP is thought to be generated at midbrain level (Buchwald and Huang, 1975; Thornton and Hawkes, 1976) and represents activity after the fourth synaptic level. Its increased latency probably reflects delays and low excitability in the brainstem pathway.

The electrophysiological and clinical changes in these patients with multiple sclerosis are all con- 
Table 4 Statistical significance, $p$, of the mean CNV amplitudes recorded before and during stimulation, with the stimulator switched on or off and with or without motivation. Paired t test was used

\begin{tabular}{|c|c|c|c|c|c|c|}
\hline & \multicolumn{2}{|c|}{ Before stimulation } & \multicolumn{2}{|c|}{ Stimulator on } & \multicolumn{2}{|c|}{ Stimulator off } \\
\hline & Motivated & Unmotivated & Motivated & Unmotivated & Motivated & Unmotivated \\
\hline $\begin{array}{l}\text { Before stimulatio } \\
\text { Motivated } \\
\text { Unmotivated }\end{array}$ & - & $\begin{array}{l}0.01 \\
-\end{array}$ & $\begin{array}{l}\text { NS } \\
\text { NS }\end{array}$ & $\begin{array}{l}0.01 \\
\text { NS }\end{array}$ & $\begin{array}{l}\text { NS } \\
\text { NS }\end{array}$ & $\begin{array}{l}0.01 \\
\text { NS }\end{array}$ \\
\hline $\begin{array}{l}\text { Stimulator on } \\
\text { Motivated } \\
\text { Unmotivated }\end{array}$ & $=$ & - & - & $\begin{array}{l}0.05 \\
-\end{array}$ & $\begin{array}{l}\text { NS } \\
\text { NS }\end{array}$ & $\begin{array}{l}0.01 \\
\text { NS }\end{array}$ \\
\hline $\begin{array}{l}\text { Stimulator off } \\
\text { Motivated } \\
\text { Unmotivated }\end{array}$ & $=$ & 二 & $=$ & $=$ & $=$ & $\underline{0.02}$ \\
\hline
\end{tabular}

NS $=$ not significant, $p>0.05 . n=7$.

sistent with the hypothesis that SCS acts primarily on spinal cord and brainstem mechanisms. It is difficult to envisage SCS having any effect on the demyelination seen in multiple sclerosis. Therefore it would not be expected to improve the conduction velocity unless some change occurs in the microenvironment-a reduction in calcium ions, for example-which would improve conduction. This and other possibilities have been discussed previously (Illis et al., 1978), and it has been suggested that, as SCS for pain may involve an enkephalin releasing system, SCS for neurological deficit may also involve neurotransmitter release.

\section{NEUROPHYSIOLOGICAL CHANGES AND CLINICAL}

RESULTS

Not all patients respond clinically to SCS and, although one would like to predict the likely responders, these evoked potential studies have not proved helpful for this. Some of the patients showing improved CSEP and BAEP did not show a worthwhile clinical response, but at the beginning of this study the importance of achieving a bilateral sensation in the legs by stimulation was not appreciated. It was quite clear, however, that patients with severely disturbed potentials could improve clinically so poor potentials are not a contraindication to a trial of epidural SCS. Of the patients studied, those who improved clinically all showed some improvement in their evoked potentials. We are, therefore, of the opinion that neurophysiological tests are a valuable adjunct to the study of treatment of patients with multiple sclerosis. There is, however, a need for more detailed serial studies of clinical and electrophysiological changes in patients with this disease.

This work is supported by the Medical Research Council. E El-Negamy was supported by the Arab Republic of Egypt. An equipment grant was provided by the Wessex Regional Health Authority.
The CNV recordings were carried out by the Clinical Measurement Service of the Royal Army Medical Corps. We would like to thank Miss Gillian Green for secretarial assistance.

\section{References}

Abraham, P., Docherty, T., and Spencer, S. (1978). Cerebral event related potentials and spinal cord stimulation. Electroencephalography and Clinical Neurophysiology, 44, $132 \mathrm{P}$.

Abraham, P., Docherty, T., Spencer, S., Cook, A. L., Oygar, A., Illis, L. S., and Sedgwick, E. M. (1979). Spinal cord stimulation and event-related potentials. In Multidisciplinary Perspectives in Event Related Brain Potential Research. Edited by D. A. Otto. US Government Printing Office: Washingten DC. In press.

Blair, R. D. G., Lee, R. G., and Vanderlinden, G. (1975). Dorsal column stimulation: Its effect on the somatosensory evoked responie. Archives of Neurology (Chicago), 32, 826-829.

Buchwald, J. S., and Huang, C. H. (1975). Far-field acoustic response: origins in the cat. Science, 189, 382-384.

Cook, A. W., and Weinstein, S. (1973). Chronic dorsal column stimulation in multiple sclerosis. New York State Journal of Medicine, 73, 2826.

El-Negamy, E. (1978). Subcortical Somatosensory Evoked Potentials Studied in Man. Dostoral thesis, University of Southampton.

El-Negamy, E., and Sedgwick, E. M. (1978). Properties of a spinal somatosensory evoked potential recorded in man. Journal of Neurology, Neurosurgery, and Psychiatry, 41, 762-768.

Hawkes, C. H., Wyke, M., Desmond, A., Bultitude, M., Small, D., Jones, S., and Robinson, K. (1978). Epidural stimulation in 21 patients with multiple sclerosis. In Advances in External Control of Human Extremities. Proceedings of the Sixth International Conference on External Control of Human Extremities, pp. 603-606. Yugoslav Committee for Electronics and Automation: Belgrade.

Illis, L. S., Sedgwick, E. M., Oygar, A. E., and Sabbahi Awadalla, M. A. (1976). Dorsal column 
stimulation in the rehabilitation of patients with multiple sclerosis. Lancet, 1, 1383-1386.

Illis, L. S., Sedgwick, E. M., and Tallis, R. C. (1978). Evaluation of possible mechanisms of action of spinal cord stimulation. In Proceedings of the Sixth International Symposium on External Control of Human Extremities, pp. 647-656. Yugoslav Committee for Electronics and Automation: Belgrade.

Illis, L. S., Sedgwick, E. M., and Tallis, R. C. (1980). Spinal cord stimulation in multiple sclerosis: clinical results. Journal of Neurology, Neurosurgery, and Psychiatry, 43, 1-14.

Jones, S. J. (1977). Short latency potentials recorded from the neck and scalp following median nerve stimulation in man. Electroencephalography and Clinical Neurophysiology, 43, 853-863.

Larson, S. J., Sances, A., Riegel, D. H., Meyer, G. A., Dallmann, D. E., and Swiontek, T. (1974). Neurophysiological effects of dorsal column stimulation in man and monkey. Journal of Neurosurgery, 41, 217-223.

McCallum, W. C., and Walter, W. G. (1968). The effects of attention and distraction on the contingent negative variation in normal and neurotic subjects. Electroencephalography and Clinical Neurophysiology, 25, 319-329.

Matthews, W. B., and Small, D. G. (1979). Serial recordings of visual and somatosensory evoked potentials in multiple sclerosis. Journal of the Neurological Sciences, 40, 11-21.

Robinson, K., and Rudge, P. (1978). The stability of the auditory evoked potentials in normal man and patients with multiple sclerosis. Journal of the
Neurological Sciences, 36, 147-156.

Sedgwick, E. M., and Soar, J. S. (1979). Origin of the N11 wave of the cervical somatosensory evoked potential CSEP in man. Proceedings of the International Evoked Potentials Symposium. MTP Press: London. In press.

Sedgwick, E. M., Thornton, A. R. D., El-Negamy, E., Tallis, R. C., and Illis, L. S. (1978). Electrophysiological responses associated with spinal cord stimulation. In Proceedings of the Sixth International Symposium on External Control of Human Extremities, pp. 635-647. Yugoslav Committee for Electronics and Automation: Belgrade.

Shagrass, C. (1977). Early evoked potentials. Schizophrenia Bulletin, 3, 80-92.

Small, D. G., Matthews, W. B., and Small, M. (1978). The cervical somatosensory evoked potential (SEP) in the diagnosis of multiple sclerosis. Journal of the Neurological Sciences, 35, 211-224.

Sohmer, H., and Feinmesser, M. (1967). Cochlear action potentials recorded from the external ear in man. Annals of Otology, Rhinology and Laryngology, 76, 427-435.

Thornton, A. R. D. (1975a). The measurement of surface recorded electrocochleographic responses. Scandinavian Audiology, 4, 51-58.

Thornton, A. R. D. (1975b). Statistical properties of surface recorded electrocochleographic responses. Scandinavian Audiology, 4, 91-102.

Thornton, A. R. D., and Hawkes, C. H. (1976). Neurological applications of surface recorded electrocochleography. Journal of Neurology, Neurosurgery, and Psychiatry, 39, 586-592. 